\title{
Ensuring Proper Competency in the Host Language: Contrasting Formula and the Place of Heritage Languages
}

\author{
MARIE MC ANDREW \\ University of Montreal
}

Background Context: In most immigrant-receiving societies, an important question, both for researchers and policy makers, has been the weighing of the relative efficiency of different formulas in the learning of the host language by immigrant students, especially the potential impact of specific services on social integration and the role of heritage languages.

Purpose Objectives Research Question Focus of Study: This article tries to go beyond the most conspicuous elements of these controversies to look at the variety of practices that different societies have adopted. Given the questions just raised, a specific focus is given to the degree to which such endeavors follow an immersion or specific services formula on the one hand, and to the role that they grant to heritage languages on the other. Five major immigrant-receiving societies have been chosen, and their choices regarding either issue are contrasted: Britain, two Canadian provinces (Quebec and Ontario), the United States, and Belgium (Flemish Brussels).

Research Design: To ascertain the extent to which transferable conclusions about best models and practices can be drawn from international comparison, evaluation research on the strengths and weaknesses of each of these formulas is reviewed, with a focus on their short and middle-term linguistic outcomes given the paucity of data on their long-term educational and social outcomes. In conclusion, we identify the minimum threshold of consensus regarding the policy and program conditions that foster a proper mastery of the host language by immigrant students without jeopardizing other dimensions of their school or social integration.

Conclusion/Recommendations: Three recommendations for policy makers can be drawn. First, flexibility and diversity of formula, both regarding the specific-services-versus-quickintegration dilemma and the place of heritage languages, seems a much better option than the one-size-fits-all model given the great variety found within the immigrant student popu- 
lation. Second, regardless of the model adopted, a fundamental winning condition lies in the recognition that the linguistic integration of newcomers is a collective responsibility and thus necessitates the establishment of close links between specific services, whenever they exist, and regular classrooms. Finally, research points to the necessity of focusing attention on schools and classrooms, especially pedagogical practices and teaching strategies, instead of being obsessed with models and formula.

In most immigrant-receiving societies, a very high consensus exists both among the majority and immigrant minorities regarding the necessity that the school system ensure a mastery of the host language(s), or at least the competency required to pursue further schooling. ${ }^{1}$ The latter ${ }^{2}$ indeed represents both an essential vehicle of educational and social mobility for immigrant students, and a necessary tool for intergroup exchanges and common citizenship. The policy debate in this domain has thus been much more focused on the means to achieve such a goal than on its relevance. In the last 20 years, numerous formulas have been tried and their value discussed widely, such as (1) "sink or swim" immersion in the host language, in which immigrant students are provided with very little, if any, specific support; (2) attendance in the regular classroom with supplementary language teaching, either outside or inside the classroom; (3) attending separate classes, for a few months up to a couple of years, in which students are offered intensive training in the host language. In this regard, one important question for both researchers and policy makers (and sometimes for immigrant parents themselves) has involved weighing the relative efficiency of each formula in the learning of the host language against its potential impact on students' integration. The latter has usually been associated with its more or less ethno-specific, or, to use here a more contentious term, segregative, nature.

But the most heated debate today remains the potential role that immigrant or "heritage languages" could or should play in ensuring a proper competency in the host language.

The intensity of controversy surrounding this issue is best understood when one takes into account two very important elements of the equation. On one hand, traditionally - that is to say, until the mid-20th century-heritage language teaching, which has existed in the United States, Canada, and some European countries since the 19th century, was advocated by its proponents almost exclusively from a linguistic and cultural maintenance perspective. Immigrant parents and associations settled such programs or, in rare instances, convinced public authorities to do so, mostly to ensure the retention of their language and of intergenera- 
tional links in the private or ethnic sphere (Anderson \& Boyer, 1970). Learning the host language was seen as a totally separate task, and the dominant status of the latter was thus very rarely challenged in public schools. In the 1960s, though, things changed radically when the "additive bilingualism" hypothesis became dominant in sociolinguistics (Cummins, 1989). The latter states that metalinguistic and metacognitive abilities developed in the first language are transferred to the second and that strengthening basic concepts and skills in the mother tongue will contribute to the mastery of other languages, including the host. From then on, heritage language teaching has been advocated and its integration within mainstream public schools and classrooms promoted, mostly for its impact on the acquisition of the host language, which obviously has greatly raised the visibility of the issue.

But this consensus among psycholinguists and language educators has certainly not convinced all decision makers, grassroots teachers, and even immigrant parents, not to mention "ordinary citizens," as we will see in the case studies that follow. Part of the resistance in this regard can be linked to poor planning of bilingual education, as the American experience clearly demonstrates (Greene, 1998), and other wider societal factors certainly also play a role. Indeed, in most countries, this paradigm shift occurred when the very nature of immigration was changing, as was the main normative framework that defined the integration blueprint. On the one hand, people much more diverse and different from the host community in terms of their continent of origin (i.e. non-Western), their religion, and their physical appearance ${ }^{4}$ migrated. On the other hand, the traditional assimilationist credo, and its pecking order of language and culture, was gradually discredited under the combined assault of decolonization and globalization (Kymlicka, 1995). Thus, the debate on the legitimacy of giving a greater role to heritage language teaching in the public school is often intermingled with a more fundamental fear of cultural threat or swamping by minorities, which is much more difficult to discuss rationally, especially when it remains largely unstated. ${ }^{5}$

In this article, I will try to go beyond the most conspicuous elements of these controversies to look at the variety of practices that different societies have adopted to foster mastery of the host language by immigrant students. Given the questions just raised, a special focus will be given to the degree to which such endeavors follow an immersion or a specific services formula on the one hand, and to the role that they grant to heritage languages on the other. For my comparison, I have purposely chosen five major immigrant receiving societies whose choices regarding either or both issues are contrasted: 
- Britain, which has rejected both the option of specific services and, until very recently, any significant support for heritage language teaching

- Two Canadian provinces, Quebec and Ontario, that share a certain commitment to heritage language teaching (although not to bilingual education) but differ on their model of French or English teaching within the classroom or within special classes

- The United States, where the contested formula of bilingual education is largely ethno-specific and implies a strong support for heritage languages but only on a short-term basis

- Flemish Brussels, which has adopted very innovative and fully bilingual (in fact, trilingual) programs targeting both newcomers and Flemish students.

To ascertain the extent to which we can learn transferable conclusions about best models and best practices from international comparisons, evaluation research on the strengths and weaknesses of each of these formulas will also be reviewed. Nevertheless, discussion will focus mostly on their short- and middle-term linguistic outcomes given the paucity of data, in most contexts, on their long-term educational and social outcomes. In conclusion, I will draw from each of these case studies common elements that will serve to identify some of the policy and program conditions that foster a proper mastery of the host language by immigrant students without jeopardizing other dimensions of their school or social integration. Nevertheless, both for the sake of respecting the requirement of comparative methodology (Farrell, 1979) and because of the limit of national research, I will stick to a rather minimal threshold of consensus in this regard, which, it is hoped, other collective endeavors following this volume might enrich.

\section{CASE STUDIES}

\section{GREAT BRITAIN}

Until recently, language did not play a very important role in the debate regarding the schooling of immigrant-origin students in Britain (Mason, 1995). The latter come mostly from the Commonwealth, and their motivation to learn English, in some instances even their prior knowledge of this language, usually generates a wide consensus. The linguistic difficulties experienced by newcomer students are usually linked much more to the proper mastery of the school language than on its mere learning. Moreover, the speakers of English as a second dialect, a euphemism that 
usually refers to West Indians, often experience many more learning problems than the speakers of English as a second language, especially when the latter come from the Indian subcontinent. Thus, at the end of the 1990s, the Department for Education and Employment decided to widen the financial measure that traditionally supported the teaching of English to speakers of other languages (Section 11) into the Ethnic Minority Achievement Grant, which can be applied to any student at risk regardless of whether he or she speaks English (Office for Standards in Education [OFSTED], 1999). "Race" and antiracist education are usually the main preoccupations of the educational milieu (Gillborn, 1995). It is also often difficult to distinguish practices that focus on the learning of the host language from those that aim to eradicate school failure, especially when one looks at evaluative studies.

Nevertheless, in recent years, there has been growing awareness of the specific needs of English as an additional language (EAL) students, as they are now referred to in Britain. Although still included under the Ethnic Minority Achievement Grant, the support for these students is now a separate additional program; both the Department for Education and Skills (DFES) and OFSTED, the independent body responsible for school evaluation, have published a variety of position papers and practical tools aimed at raising the educational attainment of these students (DFES, 2002, 2003, 2005; OFSTED, 2003, 2005). In this regard, given that schools and teachers often confuse the mastery of the spoken language with literacy, it is mostly the situation of advanced learners of English that is of concern.

Regarding the preferred formula for host language teaching, since the Education for All report of 1985 (Swann, 1985), the model of closed classes, which coexisted before with other formulas in which integration into the regular classroom was more important, has been largely discredited. Later, in the 1990s, the Commission for Racial Equality (CRE; 1986) even ruled that any parallel services that would have a more or less permanent basis and the voluntary or involuntary consequences of isolating students on a racial basis should be considered discriminatory. Some exceptions are allowed for immigrant students seriously lagging behind, but the burden of proof in this regard is on the school system. Even a model of integration within the regular classroom, in which immigrant students would receive linguistic support outside the classroom for a few hours a week, is looked on with distrust. Indeed, it is feared that students may miss important subjects and that separation from the others may stigmatize them. Therefore, an integrative model, in which the EAL specialist and the regular teacher team-teach, is favored, both in classrooms, and in preservice and in-service teacher training (Blair \& Bourne, 1998; 
Loewelberg \& Wass, 1997). In some schools, there may even be more than one extra "adult" in a regular classroom: The Ethnic Minority Achievement (EMA) specialist and bilingual monitors may also join, at least for specific periods, which often creates a complex teaching environment (DFES, 2002; OFSTED, 2005).

Until very recently, heritage languages were almost totally absent from this model, obviously as a language of instruction, but even as a teaching subject. Great Britain, whose lack of commitment to the European Economic Community directive of 1977 has been regularly denounced, did support a limited number of initiatives undertaken by the communities in this regard. However, hardly any links were made with the regular school system or practices that foster better mastery of English by newcomers. The British approach used to favor linguistic assimilation, although under the banner of school integration, which reflects the reality of a society in which antiracist concerns, more than multicultural preoccupations, dominate. But in the last 5 years, although support for bilingual education or host language teaching has not increased, more lip service is being paid to the benefits of multilingualism and to the recognition of the languages of EAL students within the regular classrooms. Thus, practices have slowly started moving in that direction (DFES, 2002; OFSTED, 2005).

Generally speaking, this model of immediate integration into the regular classroom seems to be supported by immigrant parents who, in other contexts, are often preoccupied by the loss of 1 or more years of schooling that the ethno-specific formula sometimes entails. Nevertheless, some have voiced dissatisfaction regarding the absence of their language (Gabb, 1989). Educational specialists and teacher unions are usually strong proponents of this approach at the level of principle, but they have regularly denounced the lack of resources that would really permit a meaningful integration into the regular classroom by newcomers. This was especially the case during the Thatcher years, which saw many cuts in the provision of ESL teachers whose team-teaching with regular teachers was often reduced to a few hours a week (Bourne \& McPake, 1991; Troyna \& Siraj-Blatchford, 1993). Moreover, various evaluations have shown that fully integrating the ESL teacher into the regular classroom is a very demanding task. The coordination at the school level must be high, as must be the professionalism of both teachers (Blair \& Bourne, 1998).

Because there is only one model of host language teaching, British research does not say a lot about preferable options in that regard. But especially in recent years, numerous studies have identified "winning conditions" that foster achievement among EAL students, although, as 
mentioned earlier, these studies are not always limited to that subgroup within the ethnic minorities (Blair \& Bourne, 1998; National Foundation for Educational Research, 2005; OFSTED, 2005). They especially stress a climate in which linguistic and cultural diversity is valued; a firm belief and commitment from the school principal and staff that every student can succeed; a common school strategy in which all involved personnel collaborate; significant links with the parents and the community; and a structured program based on a rigorous evaluation of EAL students' strengths and weaknesses, especially in the written "school" language. These conditions are very much in line with the conclusions of the American research (which we discuss later) and point toward "common sense" generic approaches to school success among nonspeakers of the host language.

\section{ONTARIO, CANADA}

In contrast to the British situation, language is a central issue in the debate regarding the school integration of immigrant students in English Canada. Various Canadian provinces, especially Ontario, experience a level of immigration, with respect to their host population, unequal to anywhere else in the world. School teachers, through their professional associations or unions, often voice concerns regarding the linguistic competencies of newcomers who, in big cities like Toronto or Vancouver, often represent the majority of the school clientele (Messier, 1997). Nevertheless, as in Britain, it is mostly the mastery of the school language by nonspeakers of English and even by underschooled Anglophone immigrants, rather than the mere knowledge of the language, that is seen as problematic.

Ontario stands as the Canadian province with the widest variety of formulas in the area of host language teaching for immigrants whose first language is not English, named there as ESL (English as a second language) students. Basically, they can be clustered according to three main models that are adopted depending on various linguistic and sociopedagogical characteristics of the new arrivals, the school level, and the immigrant density of the school milieu. This is why the evaluation of students' prior competency upon arrival, conducted centrally, is usually extremely thorough (North York Board of Education [NYBE], 1996; Toronto Board of Education [TBE], 1990). The most popular model is that of immersion in the regular classroom with some linguistic support outside the classroom, usually a few hours a week. The team-teaching model in which the ESL support teacher is integrated into the regular classroom is also increasingly encountered. But specific "closed" classes are sometimes 
offered at the high school level to immigrants strongly underschooled, usually on a short-term basis but sometimes up to a year. Nevertheless, in this instance, partial integration into regular classes for less demanding subjects, such as sports or arts, is usually provided (Messier, 1997). In the first two instances, the mandate of the ESL teacher is very widely defined. Indeed, he or she often plays the role of a pedagogical advisor to regular teachers, providing some counseling to help them adapt their pedagogical approaches to the needs of nonspeakers of English, and to the school principal when decisions must be made regarding the placement of immigrant students.

The place of heritage language teaching is also important, both when immigrants receive their English teaching within the regular classroom and when they benefit from specific services. This presence takes various forms, such as the pairing of newcomers with older students of the same linguistic background; the hiring of bilingual monitors, usually volunteers from the community; and the development of multilingual pedagogical tools that permit new arrivals to continue to acquire new knowledge in various disciplines while learning the new language (NYBE, 1995; TBE, 1994). However, in contrast with the United States, Ontario has never implemented transitory bilingual education programs for immigrant students. ${ }^{6}$ Its involvement in favor of heritage language preservation consists mainly of a traditional model of teaching the language, and not teaching in the language.

The origin of the Heritage Language Program (HLP) goes back to 1977, when the government of Ontario decided to respond to the longstanding and insistent request from mostly second- and even third-generation immigrant communities for better recognition of their language of origin within the public school system (Mc Andrew \& Cicéri, 1998). The government was compelled to act after a long struggle, and once it finally did give in, the program had very little status. It was essentially extracurricular and did not come under the Ministry of Education but under what was at the time called the Ministry of Continuing Education. No objectives, requirements, or teaching programs were put in place. The only criteria concerned the duration of the program (a maximum of 2 $1 / 2$ hours a week) and the fact that classes were not to be used to teach religion or folk culture. Over the years, the program status gradually improved. School boards with large numbers of immigrants increasingly incorporated it into their regular timetable by extending the school day at the request of parents (TBE, 1982). An article was also added to the Educational Act in 1988 that made it mandatory to any board to offer heritage language programs when 25 parents or more made such a request. Moreover, since 1990, it has been possible for students to get 
credited for the courses they receive in their community or in public schools in the 60 languages of origin under the HLP for the sake of high school diplomation (Ontario Ministry of Education and Training, 1996).

Very little research has been carried out to ascertain to what extent students do master their heritage language or to confirm the hypothesis that in doing so, they acquire a better knowledge of English. Much smaller scale research has shown, at least, that students who learn their heritage language do not do worse in English than those who do not (Laurier, Bosquet, \& Campbell, 1999). But given that there are very few formal links between ESL and heritage language programs and that the pedagogical quality of the latter varies greatly, it would be very difficult to rigorously test the relationships between both practices. Even if one limits oneself to the various formulas aiming to foster competency in the host language among immigrant students, research contrasting strengths and weaknesses in this regard is almost nonexistent. A few studies, especially from the Greater Toronto Metropolitan area (Anisef, Blais, Mc Andrew, Ungerleider, \& Sweet, 2004), document the results of immigrant students at high school exams, ${ }^{7}$ but it is impossible to use these to prove or disprove the adequacy of either models.

Nevertheless, the dominant model of immersion in the regular classroom with supplementary linguistic support outside the classroom generally seems to be the preferred option (Messier, 1997). It is considered easier to implement than the team-teaching formula, which is very pedagogically and professionally demanding, and it is more efficient in ensuring rapid learning of the language and maintaining a good level of social integration as compared with the closed classroom formula. The model is indeed seen only as a solution of last recourse for students who experience multiple learning problems or have accumulated, in their country of origin, significant school lag. But there is a very strong consensus that no winning formula has yet been found to really answer to the needs of such students.

Moreover, as in Great Britain, the two models that rely on immediate integration within the regular classroom have been criticized, both by specialists and teachers unions, as insufficiently staffed and resourced (Curtis \& Taborek, 1994). This has even recently led some to call for an extension of the closed classroom model to more students, probably under the influence of the Quebec model, a sociodemocratic province generally considered more generous than neoconservative Ontario. ${ }^{8}$

QUEBEC, CANADA

In contrast with the dominant Canadian model of ESL delivery, within or 
outside the regular classroom, the choice for an intensive teaching of French in a specific classroom in Quebec is linked with the particular linguistic situation of that province. Indeed, in that context, which holds some commonalities with that of Flemish Brussels discussed next, the very learning of French by immigrants, and not the sole mastery of a clearly dominant language, is at stake, or at least it was when the model was first adopted. It dates to 1969, before Bill 101 made attendance in French schools compulsory for both francophone and immigrant students (Mc Andrew, 2004). It was then felt that a systematic, structured long-term exposure to French was required because of the very nature of Quebec society.

But there may also be some pedagogical and linguistic value to immigrant students attending a specific reduced-ratio classroom, a model that has been adopted in France and Catalonia (Mc Andrew, 2001). It can often act as a sas between the familiar reality of the language and the culture of origin, and the sometimes harsh reality of adapting to a new environment in larger and faster paced classrooms. But, as with the American debate, the crucial issue is the transitory or permanent nature of such initiatives.

Wherever there are enough students to justify their creation, ${ }^{9}$ classes d'accueil (welcoming classes) usually consist of one specially trained French as a second language (FSL) teacher and around 15 students, who can join at any time depending on their arrival and should theoretically stay for an average of 10 months. Teaching of French is extremely well developed, including not only the mastery of the school language and the development of communication abilities but also a sensitization to the sociological reality and cultural codes of the host society. No specific role is devoted to heritage languages; the communicative approach clearly discourages any translation of concepts by the teacher in the very unlikely situation, given the presence in the Quebec school system of over 50 languages, that he or she might be able to do so.

Quebec nonetheless has a significant heritage language program (Programme d'enseignement des langues d'origine [PELO]), although not as large scale as Ontario's, created in 1977 as a counterpart to the then extremely active endeavors linked to the promotion of French. Indeed, at the time, it was believed that a message had to be sent to immigrant communities that although French was to regain its status as a common language over traditionally dominant English, multilingualism was also to be valued. In contrast to the Ontario situation, heritage language teaching has enjoyed high legitimacy from the start: It had the status of a regular school program provided by teachers paid on the same salary scale as regular teachers and under pedagogical programs designed by the 
Ministry of Education to reflect modern approaches in language teaching (Mc Andrew \& Cicéri, 1998). Also in line with the preference for interculturalism and pluralistic integration prevalent in Quebec, there was a clear focus on the lived experience and culture of immigrant and allophone students here and now, and not on the country of origin (Ministère de l'Éducation du Québec [MEQ], 1978).

However, PELO, which enrolls a little more than 7,000 students in some 14 languages, has faced some problems (Mc Andrew \& Cicéri, 1998; Mc Andrew, 2001). First, given that private education is publicly funded in Quebec, it is likely that the most committed parents of various language groups prefer to enroll their children in full-time trilingual schools rather than simply in heritage language classes within public schools. Moreover, school teachers have often shown some resistance to the integration of the program within the regular school timetable, especially in French schools, where one rarely encounters a concentration of one single linguistic group. PELO has thus been increasingly offered as an extracurricular activity before or after school. The program has also suffered from a lack of focus. Indeed, although it was justified as a support for the integration of immigrant students into the school milieu and their learning of the host language, it never had significant links with classes d'accueil, whose students are not allowed to enroll. Moreover, for a variety of reasons, PELO has been offered almost exclusively at the primary school level, where students usually experienced few difficulties in acquiring proper competency in the host language. At the high school level, very few heritage language programs, not to mention bilingual programs, exist, although the latter might have been very useful for students struggling to learn French and not fall behind in their other areas of study.

The tendency to extend the length of stay within classes d'accueil indeed has been most pronounced in high schools, although it theoretically runs contrary to the stated objective of the program. Nowadays, it is estimated that the proportion of students at that level who spend 2 or more years in classes d'accueil could be as high as 50\% (MEQ, 1998). Without fully rejecting the closed-class model, whose greater integration with the regular classroom is now fostered, alternative and more innovative endeavors-such as direct immersion with linguistic support within or outside the classroom or team-teaching between classes d'accueil and heritage language classes teachers-are now being experimented with (MEQ, 2003). Although widely supported, these initiatives have met with some resistance from the main teachers union in Montreal, which now advocates not only the maintenance of classes d'accueil but also their concentration in specific schools to ensure a greater homogeneity of students and 
better access to pedagogical resources for teachers (Mc Andrew, 2001). Although linked mostly to corporatist interests, this commitment in favor of the preservation of the unique model of classes d'accueil can also be argued on the basis of research data. But as expected from pressure groups, teachers' unions often selectively read only those that favor their stance.

Longitudinal research with various cohorts having attended classes d'accueil (Maisonneuve, 1987; MEQ, 1996) does indeed demonstrate that immigrant students experience a favorable school career throughout the system, especially if they entered into Quebec schools at the preschool or primary level. Almost $40 \%$ receive their high school certification on time, which is indeed a remarkable performance because it implies that students have been able to compensate for the year spent in classes d'accueil. But even for those who only have 1 year's lag (the price of acquiring the new language), it does seem to be a good investment because their ministerial exam results and certification rates are roughly on par with those of native-born students.

But research also shows that the "report card" of opting for a specific class model may not be as homogenously rosy. First, it is clear that when students enter the school system at the high school level, especially if they did not receive adequate prior schooling in their country of origin, their difficulties are greater. The majority of these students accumulate over 2 years of school delay, and a slightly lower percentage, almost $40 \%$, leave school without a diploma. Moreover, research based not on actual results at ministerial exams but on the perception of teachers (MEQ 1998) both at the primary and secondary level also shows a strong concern for the mastery and the level of sophistication in French that students in classes d'accueil are actually able to acquire and, most of all, develop later on while attending regular classes. The lack of linguistic models, limited solely to the classes d'accueil teachers, is probably one of the reasons for this, especially for young students with no special problems who could learn much faster in a linguistic bath, interacting with French-speaking peers.

\section{UNITED STATES}

The linguistic question has always been a central issue in the American debate regarding the schooling of immigrant students (Crawford, 1999; Hakuta, 1986). This may sound surprising, especially from an international point of view, given the overwhelming dominant role of English in the United States and in the world. Nevertheless, it is better understood when one takes into account the nature and the concentration of the 
immigrant population in the country. Because the selection of independent candidates is relatively limited, the migratory flux comprises mainly refugees and illegal immigrants, among which Spanish speakers from Mexico and Central and South America are heavily represented (76.9\% in 2001-2002; Zehler et al., 2003). Those migrants are also concentrated in some states, such as California and Florida, where a longer established Hispanic community is in place that enjoys a high degree of institutional completeness. Thus, the very adoption of English as a common language is sometimes considered potentially jeopardized there. Moreover, because Hispanic students are usually underprivileged, their schooling presents numerous challenges (Passell, 1998; Waldinger, 1997).

As far as one can say something true about a very complex society that includes 50 states and 50 school systems, the dominant model for the teaching of the host language in the United States has been, from 1968 to the late 1990s, transitory bilingual education (Crawford; Fishman, 1976). In such a formula, schooling of new arrivals is conducted in their language of origin while the teaching of English gradually increases through schooling until it becomes the only language of instruction, although the heritage language continues to be taught as a subject. Under the Bilingual Education Act of 1968, now abrogated, the program was clearly compensatory. The aim was not, at least theoretically, the maintenance of languages and cultures, as is the case in the heritage language programs of Ontario and Quebec, but better educational opportunities for immigrant students. The implementation of bilingual education was indeed part of a wider set of initiatives against poverty and inequality in education, which President Johnson had summarized with his campaign slogan, "The Great Society."

Since the inception of the program, tension has existed between, on the one hand, the government and the majority community, who have always considered the teaching in and of heritage languages to be an integration tool, and minority communities on the other, who have constantly tried to see it gain a more permanent status (Galindo, 1997; Kjolseth, 1975). In 1973, an important ruling from the Supreme Court did confirm that bilingual education had to be both compensatory and transitory. Indeed, although it supported the claims of students and parents of Chinese origin that the San Francisco board was obliged to offer pedagogical support to linguistic minorities, it nevertheless clearly stated that the nature of such support (either bilingual programs or supplementary ESL programs) had to be based on their relative efficiency in promoting equality in education and not on any specific right of the minority community to receive state support for their language and culture. 
Nevertheless, in many contexts, some minority groups have used the ambiguity of the legislation and their political power to attain the continuation of bilingual classes throughout elementary and even high school levels. The decentralization of the American school system has been a useful tool for them in this regard: Many states have adopted bilingual education acts, which were not only permissive but also mandatory (Garcia \& Morgan, 1997).

Under these pressures, in the mid-1980s, the federal government opened the door on an experimental basis to programs with a less exclusively compensatory focus: developmental bilingual education (Crawford, 1997b). In some instances, these programs foster the presence of nonspeakers of the targeted language (they are then named twoway bilingual education or dual language education). At the beginning, this inclusion was aimed mostly at rendering permanent programs compatible with the Antidiscrimination Act, which forbids segregation, other than temporary, on an ethno-linguistic or "racial" basis in the United States (U.S. Department of Education [USDE], 1995; Crawford, 1997b). But recently, these programs have experienced a genuine growth of popularity, although limited, among majority parents (Lindholm-Leary, 2000).

The popularity of compensatory bilingual education reached its peak at the end of the 1980s, when it was estimated that over half a million students, learning mostly Spanish, were profiting from such programs in over 40 states (Ovando \& Collier, 1998). Since the 1990s, however, it has been under strong attack. Its opponents (Crawford, 1997a; English for the Children, 1997a, 1997b; McQuillan \& Tse, 1996) denounce it as a costly and ineffective approach for the learning of English that is too often used, especially by the Hispanic community, as a cultural and linguistic maintenance program. Thus, it would generally not ensure proper competency in the host language for immigrant students and would often turn into second-class segregated schooling, especially for underprivileged students in high schools. The movement against compensatory bilingual education coincided with greater conservatism in the wider society and an increased concern about the status of English as a common language. This led to different states outlawing or strongly limiting the role of heritage languages in their services for limited English proficient (LEP) students (in the United States also called, more positively, English language learners (ELLs; California State Board of Education, 1998; Ovando \& Collier, 1998; The Stanford Working Group, 1995). The most notorious case is California, where proposition 227, English Language Education for Immigrant Children, which actually 
targeted the abolition of bilingual education, was supported by over $70 \%$ of the voters.

There has since been a proliferation of opposing formulas in which exclusive teaching of English is prioritized, and the role of heritage languages is much less important, if not almost nonexistent (e.g., sheltered instruction, structured immersion, and ESL pull-out). A recent report (Zehler et al., 2003) has found that from 1992 to 2002, although the variety of formulas among and within states has significantly increased, 57\% LEP students now receive language services only in English (as compared with one third 10 years ago). At the other end of the continuum, the proportion of students benefiting from relatively extensive bilingual education programs decreased from $37 \%$ to $17 \% .^{10}$

But bilingual education is far from dead. In 1999-2000, over $80 \%$ of American states still offered bilingual programs (USDE, 2002), and the proponents of such an approach have strongly fought the arguments of their opponents. They have stressed that most of the obsession regarding the status of English in the United States is meaningless and reflects more racism or nativism than real concern (Crawford, 1999; Krashen, 1996). Moreover, proponents have argued that research shows that bilingual programs are more efficient than, or at least as efficient as, other approaches to the learning of English.

Nevertheless, research regarding the issue of bilingual education is much less conclusive than both parties would have us believe. Fundamental studies in psycho-linguistics carried out with individual learners, and the bulk of "immersion programs" literature, which generally concerns linguistically dominant groups, support the additive bilingualism hypothesis (Artigal, 1991; Cummins, 1989). But evaluation studies of "real" bilingual programs targeting immigrant students have held more mixed results, partially due to the methodological complexity of proving that, "all things being equal," it is better for immigrant students to continue to develop mastery of their heritage language while learning the host languages ${ }^{11}$ (Dolson \& Meyer, 1992; Greene, 1998). More recently, with the diversification of formulas, new studies concerning their relative strengths and weaknesses regarding the learning of English in the short term, and on academic achievement in the long run, have been undertaken or are under way (Center for Applied Linguistics, 2005a, 2005b; Thomas \& Collier, 2002). Up to now, although most studies have not borne out their full results, they seem to point toward a greater impact of formulas when there is a significant presence of students' heritage languages. But the debate is far from exhausted, and it is most likely that proponents of English-only or mainly English services will come with competing findings. So, while specialists and opinion-makers 
continue to fight, school authorities in most states make decisions in this regard based on a mix of personal assumptions, community pressure, and short-term cost-benefit analyses.

Potentially more fruitful reflections for an international audience interested in the transferability of American research to their own context can be found in the meta-analysis of 30 years of research on efficient practices in the area of host language teaching, which was undertaken for the USDE by the National Research Council (1997). It first stresses that what is important is not the model, but rather the very different pedagogical practices that may hide behind similar labels. Efficient approaches usually imply a structured program that systematically fosters competency in the host language, an opening to linguistic diversity and a minimal presence of heritage languages, and a strong integration of LEP students with their English mother-tongue peers. The report also stresses that the "school effect" seems to be more important, in any given program, than the model effect (i.e., schools in which linguistic minority students succeed are usually overperforming schools in general). So, as found in Britain, the dedication of teachers and their belief in the capacity of students to succeed, good leadership from the school principal, and close links with parents are also winning conditions (Johnson \& Acera, 1999; Sammons, Hillman, \& Mortimore, 1995).

\section{BELGIUM}

Nationwide, there is very little room for maneuvering in Belgium regarding the language of instruction, which must be Dutch in Flanders and French in Wallonia. Nevertheless, the capital, Brussels, is a free linguistic market where parents can choose the language of schooling for their children. It is also, with $40 \%$ foreigners, the main reception center of extremely socioeconomically polarized immigration (both European Union civil servants and recently arrived or longer settled refugees and immigrants from developing countries). This immigrant population is an often sought-after clientele for competing linguistic school sectors: For obvious reasons, Dutch medium schools are usually much less popular than their French medium counterparts in this regard (Boussetta, 2000; Janssens \& Mc Andrew, 2004).

For this reason, it is likely that the most innovative approaches regarding the teaching of the host language and of heritage languages have been developed in that sector: namely, the trilingual program started in Le Foyer in 1981. At its peak, the formula touched almost half of the Dutch preschool and primary schools in Brussels (Byram \& Leman, 1990; Leman, 1993), although it has stagnated since the mid-1990s because of 
some resistance from the school authorities (Top \& de Smedt, 2005). Nowadays, they tolerate this experiment but do not really encourage it. This change of mood can probably be linked to the increasing number of immigrant students in Dutch-medium schools, which makes attractive measures less of a necessity but also raises concern among teachers and school personnel (Roosens, 2007).

In contrast with the U.S. experience, in which the aim of achieving twoway bilingual education has been met with limited success as discussed, the Foyer experiment targets as much the Dutch-speaking students as the newly arrived speakers of other languages. Both are expected to have acquired, at the end of their primary schooling, a balanced trilingualism and the intercultural competencies needed to live together. Such a model involves some instruction periods during which both linguistic groups are segregated. The latter can be as high as $50 \%$ in preschool and during the first 2 years of primary school, but they gradually decrease during the second half of primary schooling, when both groups are integrated for up to $90 \%$ of the instruction periods. At that time, students share the same classes for regular disciplines given in Dutch and for the teaching of French and a specific heritage language-Italian most of the time, but also Spanish and Turkish.

The Foyer model has been the subject of a wide-scale evaluation toward the end of the 1980s (Byram, 1990a, 1990b; Jaspaert \& Lemmens, 1990; Smeekens, 1990). It showed that non-Dutch speakers who attended the trilingual program had the same competencies in Dutch than their peers exclusively schooled in that language. Nevertheless, this control group was somewhat limited, because at that time, there were very few immigrant students in the regular Dutch school system. For that reason, it was not possible to prove the claims of the proponents of bilingual education (i.e., that the performance in the host language of students benefiting from such a formula is actually higher than that of students not learning their heritage language). The data also showed that the performance in Dutch of non-native speakers of that language was, as expected, weaker than that of native Dutch speakers and that they used the language much less. They also had a much lower affective relationship with and commitment toward it, but this latter tendency can be linked not to the maintenance of the heritage language but rather to the specific sociolinguistic situation of Flemish in Brussels.

Although the model seems very beneficial for both groups of students, the main challenge was experienced by Flemish teachers, who often came from outside Brussels and were therefore not used to multilingualism or multiculturalism. They were especially uncomfortable with the presence of other languages in the school setting, especially French, 
which some immigrant groups used as a second language. Nevertheless, one of the most positive aspects of the experience was the link it permitted to develop between regular teachers, usually native-born Dutch speakers, and heritage language teachers, usually foreign born, in contrast to the widely expressed criticism regarding the isolation of heritage language teaching in many countries.

In other parts of Flanders, heritage language teaching follows a very traditional, nonintegrated community-controlled model, which does not present any heuristic interest in the debate discussed in this article (Roosens, 2007). In Wallonia, though, the heritage language program, which used to be more or less on the same line, has experienced an interesting evolution toward a greater status (Communauté Française de Belgique, 1997; Sensi, 1995). It can now be integrated into the regular school program and be open to nonspeakers of the target language. The most innovative approach now under experimentation is a model in which the heritage language teacher works within the regular classroom in team-teaching with the regular teacher. This formula shares common elements and differences, both with direct integration into the regular classrooms with linguistic support, which is found in Great Britain and in Ontario (with a much higher status for the languages of origin), and with bilingual education in the United States (avoiding its permanency and potential for segregation). The Charte $d u$ Partenariat, signed by the Wallonian authorities with various countries of origin, attempts to reconcile two competing objectives of heritage language teaching: the support for the learning of the host language, and the preservation of language and culture of immigrant youth. Whether this is fully possible is certainly open to debate, especially given that there is currently no evaluation of this very new initiative. Nevertheless, based on some informal interviews conducted by the author, it does seem that preserving the equilibrium between those two objectives is not easy, and it is generally done at the expense of the maintenance of heritage languages. Foreign teachers do complain that they are often reduced to playing the role of assistant to regular teachers who clearly give priority to the learning of French rather than fully assuming their responsibilities of teaching the heritage language.

\section{CONCLUSION}

What can we learn, from a policy point of view, from this brief overview of how five different immigration societies tackle the problem of ensuring a proper competency in the host language among newcomer students? Although evaluative research on many programs is limited, 
especially regarding their long-term consequences, there are certainly relevant lessons to be learned regarding the strengths and weaknesses of different formulas, as well as some winning implementation conditions. But the latter must be stated in terms general enough not to imply a direct transferability of policies and practices between contexts, which are very different in terms of both immigration and diversity issues, and generic characteristics of their school systems.

The first obvious conclusion emerging from our comparative analysis, which may be seen as bad news or good news by policy makers often pressured to adopt foreign models, is that none of the formulas reviewed has emerged as a panacea, whether one looks at the immersion-versus-specific-services debate or at the place of heritage languages.

In the first instance, in each of the societies presented, limitations of the chosen formulas have been identified. Everywhere, the same difficult tension exists between the need to offer some specific treatment to new arrivals in their host language learning process (i.e., a clear recognition that the "sink or swim" approach is a failure), and the very real possibility that this support rigidifies into permanent streaming (whether this results from teachers' resistance, or community desire for cultural maintenance). In each context, although different decisions may be made, the age of the student and his or her linguistic and pedagogical characteristics are key elements to deciding, on a continuum of services, when the regular classrooms should assume the lead. And as expected, the success of any given formula is always stronger with students arriving early with positive socioeducational prerequisites as compared with heavy clienteles (i.e., students who migrate during adolescence with no or insufficient schooling in their country of origin). For heavy clienteles, many alternative approaches have been tried, but none is a clear success. One can also witness an important gap between theoretical models and their actual implementation in the field. Thus, often in societies that favor rapid integration into regular classrooms, such as Great Britain or Ontario, the resources promised when specific services were abolished did not materialize. Conversely, in societies in which specific services are favored (such as the United States or Quebec), the rhetoric pretending that they are only temporary and that maximum links with regular classrooms will be ensured is far from always being actualized, and permanent marginalization tendencies often emerge.

Regarding the place of heritage languages, research would indicate that, "all things being equal" (i.e., whenever other conditions for quality programs are in place), it is a plus in the learning of the host language, notwithstanding the cultural, linguistic, and economic value it may have, both for the minorities themselves and for the host country. 
Nevertheless, implementation is much more complex and sometimes proves to be an impossible task. On the one hand, if one chooses bilingual education, it clearly contributes, although theoretically only on a short-term basis, to the segregation of immigrant students, bringing one back to the stance that one takes in the first debate. This could be counteracted by programs that ensure an equal presence of nonspeakers of the target language, but with the exception of unusual situations (such as the small school market of Brussels), such an endeavor is not usually successful, especially for immigrant nondominant languages. ${ }^{12}$ Moreover, the organization of effective bilingual education programs requires that the immigrant population consist of a limited number of geographically concentrated linguistic groups, a situation rarely encountered in modern immigration societies (with the possible exception of the United States).

On the other hand, if one favors instead a mere teaching of heritage languages, most of the challenges linked to bilingual education can be eliminated. But the pedagogical impact of such endeavors on competency in the host language is much more questionable, especially given the lack of relationship that usually exists between those two objectives. But some alternative programs in Ontario, Quebec, and francophone Belgium, where heritage language teaching and teachers are much more associated with English or French teaching and teachers, represent promising avenues.

Even given this ambiguity and complexity, it is possible to draw three conclusions about implementation conditions that may help policy making in the area of host language learning.

First, flexibility and diversity of formula seem a much better option than the one-size-fits-all model. Immigrant students are themselves very diverse in terms of age, socioeconomic and linguistic characteristics, prior schooling, and educational expectation. In this regard, a very clear distinction exists between primary and secondary students. Even societies that clearly favor quick integration into the regular classroom, such as Britain or English Canada, do make an exception to this rule for latearrival students. Conversely, societies that used to consider specific services the most effective means of acquiring host language, such as the United States and Quebec, recently have been experimenting lighter approaches, especially for younger students. Age, but mostly socioeconomic condition and prior schooling experience, also should play a major role in determining the place of heritage languages in whichever formula one privileges for a given student. Some heavy clientele may indeed need access to full bilingual programs to master the host language without losing their sense of self-worth or accumulating academic deficits that would hinder their educational mobility. But for many 
students, especially the younger ones, a certain degree of symbolic recognition of their mother tongue will be sufficient to generate the sense of security needed for the effective learning of a new language, as confirmed by an American meta-analysis (National Research Council, 1997) and exemplified in Europe by the new popularity of language awareness programs.

Second, regardless of the model adopted, a fundamental winning condition lies in the clear recognition that the linguistic integration of newcomers is the collective responsibility of the entire school and thus necessitates the establishment of close links between specific services, whenever they exist, and regular classrooms. Obviously, models that favor quick integration into the regular classroom start with an advantage in this regard, but one should not be misled into believing that the mere existence of such a formula necessarily ensures a general involvement in favor of immigrant students. Preservice and in-service training of regular teachers in the challenges of welcoming and integrating nonspeakers of the host language, even when the students have received specific services, is thus as important as planning language programs.

Finally, most research reminds us of the necessity of focusing our debates on schools and classrooms, especially pedagogical practices and teaching strategies, instead of being obsessed with models and formulas. This change of paradigm requires that we widen our discussion on host language learning. It needs to be better informed by what we already know about school success in general and within longer established cultural communities so that we develop a renewed expertise in efficient approaches targeting new arrivals. Indeed, although many conclusions from the "effective school" literature may sound like evidences, implementing them at the local level is often an important challenge. Promoting an ethos of success for all and of equity within the school system may thus require more generic approaches to improve attitudes toward diversity, both among the school personnel and the general public.

\section{Notes}

1. We refer here to the language(s) most often used in the public sphere and in the school system. We prefer the term host to the two other competing concepts of official or dominant languages for two reasons. First, as we will see in the U.S. case study, not every country has an official language, and second, in some contexts, such as Brussels or Montreal, the same languages may not be dominant when we refer to the market or to the institutional sphere.

2. From now on, to simplify the text, we will only use the singular, but it must be understood that in some countries we are referring to two languages. 
3. The concept of heritage languages is used when referring to children born in the new country or, even in the case of immigrants, in societies that promote a multicultural ideology, to send the message that other languages are part of the common cultural heritage. For this reason and to avoid the exclusionary message sent by the term immigrant languages, we will use heritage languages.

4. This is what we used to refer to as their race before the term was scientifically and socially discredited.

5. For example, a few years ago, following an attempt by Christian Lebanese parents to obtain heritage language classes in Arabic in a major public school in the Montreal area, a populist newspaper headlined, "Arabs Impose the Teaching of [Mohammed's] Language," and a leading local newspaper in Scarborough, a suburb of Toronto, predicted that the neighborhood would be totally swamped by Chinese businesses and housing complexes if the local board agreed to offer heritage language teaching in that language (Mc Andrew \& Cicéri, 1998). This nasty treatment is not exclusive to Canada, as exemplified in some of the hysteria surrounding the bilingual education controversy in the United States, and other minority educational issues in Europe.

6. In Canada, bilingual programs are only offered in some Western provinces, but with a few exceptions, they do not target new arrivals but second- or third-generation students already fluent in English but whose parents have demonstrated an attachment to the preservation of their heritage languages. Thus, most of these programs follow a permanent, balanced cultural maintenance model of bilingual education.

7. They clearly demonstrate that the pecking order in this regard is far from being directly linked to linguistic distance between English and different languages. In this respect, as in Great Britain, the situation of English as a second dialect is of greater concern than those of various other linguistic groups, in which Chinese speakers succeed particularly well.

8. At least until the last elections, when the situation in both provinces was somehow reversed.

9. The Quebec Education Act guarantees access to FSL teaching for any new arrival, but in the outlying regions where there is much less immigration, one also finds the direct immersion into the regular classroom, with specific linguistic support outside the classroom.

10. An even more preoccupying trend revealed by this study is that the percentage of LEP students receiving only mainstream education without language services increased from $3.5 \%$ to $11.7 \%$.

11. For example, are we comparing equivalent groups of students when contrasting formulas? What educational practices lie behind the label of bilingual education? Are all "bilingual programs" similar? Should we expect all academic problems of immigrant students to be solved by adopting one language formula, especially when they belong to socioeconomically deprived groups?

12. Let's remember that the great majority of balanced bilingual programs in the world - that is, with equal representation of speakers of both communities-involve official or national minorities' languages (Crawford, 1999; Fishman, 1976).

\section{References}

Anderson, T., \& Boyer, M. (1970). Bilingual schooling in the United States. Austin, TX: Educational Development Laboratory. 
Anisef, P., Blais, J.-G., Mc Andrew, M., Ungerleider, C., \& Sweet, R. (2004). Academic performance and educational mobility of youth of immigrant origin in Canada: What can we learn from provincial data banks? Ottawa, Ontario: Rapport de recherche. Immigration et métropoles/CIC.

Artigal, J. P. (1991). The Catalan Immersion Program: A European point of view. Norwood, NJ: Ablex.

Blair, M., \& Bourne, J. (1998). Making the difference: Teaching and learning strategies in successful multiethnic schools (Research Report No. 59). London: The Open University, Department for Education and Employment.

Bourne, J., \& McPake, J. (1991). Partnership teaching: Cooperative teaching strategies for language support in multilingual classrooms. London: HMSO.

Boussetta, H. (2000). Intégration des immigrés et division communautaire: l'exemple de la Belgique [Integration of immigrants and intercommunity divisions: The case of Belgium]. In M. Mc Andrew \& F. Gagnon (Eds.), Relations ethniques et éducation dans les sociétés divisées: Québec, Irlande du Nord, Catalogne et Belgique (pp. 59-85). Montreal, Quebec/ Paris: L'Harmattan.

Byram, M. (1990a). Return to the home country: The "necessary dream" in ethnic identity. In M. Byram \& J. Leman (Eds.), Bicultural and trilingual education: The Foyer model in Brussels (pp. 77-94). Clevedon, England: Multilingual Matters.

Byram, M. (1990b). Teachers and pupils: The significance of cultural identity. In M. Byram \& J. Leman (Eds.), Bicultural and trilingual education: The Foyer model in Brussels (pp. 126-135). Clevedon, England: Multilingual Matters.

Byram, M., \& Leman, J. (1990). Bilingual and trilingual education: The Foyer model in Brussels. Philadelphia: Multilingual Matters.

California State Board of Education. (1998). California State Board of Education: Title 5. California Code of Regulation, Division 1, Chapter 11, Sub-Chapter 4-English Language Learner Education.

Center for Applied Linguistics. (2005a). The effect of sheltered instruction on the achievement of limited English proficient students. Project Description. Funded by Office of Educational Research on Improvement. U.S. Department of Education. Retrieved July 8, 2008, from http://www.cal.org/crede

Center for Applied Linguistics. (2005b). Two-way immersion education. Project Description. Funders: Center for Research on Education Diversity and Excellence, National Institute for Education of At-Risk Students, Office of Educational Research on Improvement. U.S. Department of Education. Retrieved July 8, 2008, from http://www.cal.org/crede/twoway.htm

Commission for Racial Equality. (1986). Teaching English as a second language (Report of a formal investigation). London: Calderdale Local Education Authority.

Communauté Française de Belgique. (1997). Programme LCO. Charte du partenariat 19972000. Scolarisation en milieu multiculturel [The Language and Culture of Origin Program: The Partnership Charter 1997-2000. Education in a multiethnic setting]. Brussels, Belgium: Author.

Crawford, J. (1997a). The campaign against proposition 227: A post-mortem. Bilingual Research Journal, 21(1), 1-29.

Crawford, J. (1997b). Best evidence research foundation of the Bilingual Education Act. Washington, DC: National Clearinghouse for Bilingual Education.

Crawford, J. (1999). Bilingual education: History, politics, theory and practice. Los Angeles: Bilingual Education Services. 
Cummins, J. (1989). Empowering minority students. Sacramento: California Association for Bilingual Education.

Curtis, L., \& Taborek, E. (1994). Presentation by TESL Ontario to the Royal Commission on Learning. Contact, 19(3), 23-26.

Department for Education and Skills. (2002, September). The National Literacy Strategy: Supporting pupils learning English as an additional language. London: Author.

Department for Education and Skills. (2003, March). Aiming high: Raising the achievement of minority ethnic pupils. London: Author.

Department for Education and Skills. (2005, April). Aiming high: Guidance on the assessment evaluation of pupils learning English as an additional language. London: Author.

Dolson, D. T., \& Meyer, J. (1992). Longitudinal study of three program models for language minority students: A critical examination of reported findings. Bilingual Research Journal, $16,105-157$.

English for the Children. (1997a). The 1997-1998 California English for the Children Initiative. Retrieved March 5, 2006, from http://www.onenation.org/

English for the Children. (1997b). Proposition 227. The 1997-1998 California English for the Children Initiative. Retrieved March 5, 2006, from http://www.onenation.org/

Farrell, J. P. (1979). The necessity of comparisons in the study of education: The salience of science and the problem of comparability. Comparative Education Review, 23, 3-16.

Fishman, J. (1976). Bilingual education: An international sociological perspective. Rowley, MA: Newbury House.

Gabb, M. (1989). An ESL perspective for community languages in the curriculum. In J. Geach \& J. Broadbent (Eds.), Coherence in diversity: Britain's multilingual classroom (pp. 43-51). London: CILT.

Galindo, R. (1997). Language wars: The ideological dimensions of the debates on bilingual education. Bilingual Research Journal, 21(2-3), 103-141.

Garcia, A., \& Morgan, C. (1997). A 50 state survey of requirements for the education of language minority children. Washington, DC: Center for Equal Opportunity.

Gillborn, D. (1995). Racism and antiracism in real schools: Theory, policy, practices. Buckingham, England: Open University Press.

Greene, J. (1998). A meta-analysis of the effectiveness of bilingual education. Claremont, CA: Thòmas Rivera Policy Center.

Hakuta, K. (1986). Mirror of language: The debate on bilingualism. New York: Basic Books.

Janssens, R., \& Mc Andrew, M. (2004). The role of schooling and the maintenance and transformation of ethnic boundaries between linguistic communities: Contrasting Quebec and Belgium. Canadian Ethnic Studies, 36(3), 61-83.

Jaspaert, K., \& Lemmens, G. (1990). Linguistic evaluation of Dutch as a third language. In M. Byram \& J. Leman (Eds.), Bicultural and trilingual education: The Foyer model in Brussels (pp. 30-56). Clevedon, England: Multilingual Matters.

Johnson, J., \& Acera, R. (1999). Hope for urban education: A study of nine high performing, high poverty urban elementary schools [Report of method to the U.S. Department of Education, Planning and Evaluation Services]. Houston: Charles A. Donna Center, University of Texas at Houston.

Kjolseth, R. (1975). Bilingual education in the U.S.: For assimilation or pluralism. In B. Spolsky, (Ed.), Language education of minority children (pp. 94-121). Rowley, MA: Newbury House.

Krashen, S. (1996). Under attack: The case against bilingual education. Culver City, CA: Language Education Associates. 
Kymlicka, W. (1995). Multicultural citizenship. Oxford, England: Clarendon Press.

Laurier M. D., Bosquet, M., \& Campbell, J. (1999). L'enseignement des langues d'origine: un état de la situation dans différents contextes [The teaching of heritage languages: The state of the art in various contexts]. Rapport remis au ministère de l'Éducation, Direction des services aux communautés culturelles, avril. Centre de langues patrimoniales/ CEETUM, Université de Montréal.

Leman, J. (1993). Les politiques d'éducation interculturelle dans les communautés française et flamande de Belgique [Intercultural education policies in the French and Fleming communities in Belgium]. Recherches en éducation: théorie et pratique, 15, 33-40.

Lindholm-Leary, K. (2000). Bi-literacy for a global society: An IED book on dual language education. National Clearing House for Bilingual Education. Washington, DC: George Washington University.

Loewelberg, N., \& Wass, B. (1997). Provision for the development of the linguistic proficiency of young immigrants in England and France: A comparative study. Comparative Education, 33, 395-409.

Maisonneuve, D. (1987). Le cheminement scolaire des élèves ayant séjourné en classe d'accueil [The educational progress of students who attended welcoming classes]. Montreal, Quebec: MEQ, Direction générale de la recherche et du développement.

Mason, D. (1995). Race and ethnicity in modern Britain. Oxford, England: Oxford University Press.

Mc Andrew, M. (2001). Immigration et diversité à l'école. Le débat québécois dans une perspective comparative [Immigration and diversity in schools: The Quebec debate in a comparative perspective]. English version. Montreal, Quebec: Les Presses de l'Université de Montréal.

Mc Andrew, M. (2004). Immigration, pluralism and education. In A. Gagnon (Ed.), Quebec: State and society (2nd ed., pp. 307-328). Peterborough, Ontario: Broadview Press.

Mc Andrew, M., \& Cicéri, C. (1998). Immigration, diversity and multilingual education: The Canadian example. Zeitschrift für internationale erziehungs- und socialwissenschaftliche Forschung, 15(2), 295-322.

McQuillan, J., \& Tsé, L. (1996). Does research matter? An analysis of media opinion on bilingual education, 1894-1994. Bilingual Research Journal, 20, 1-27.

Messier, M. (1997). Les modèles de services réservés aux élèves nouveaux arrivants: une étude comparée entre Montréal et Toronto [Models of services targeting new arrival students: A comparative study between Toronto and Montreal]. Montreal, Quebec: Immigration et métropoles.

Ministère de l'Éducation du Québec. (1978). Projet d'enseignement des langues d'origine (PELO) [The Heritage Language Teaching Program (HLTP): General framework of the project]. Cadre général du projet. Montreal, Quebec: Author.

Ministère de l'Éducation du Québec. (1996). Le point sur les services d'accueil et de francisation de l'école publique québécoise. Pratiques actuelles et résultats des élèves [An assessment of welcoming and language teaching services in Quebecpublic schools: Current practices and students' results]. Montreal, Quebec: Direction des services aux communautés culturelles.

Ministère de l'Éducation du Québec. (1998). Une école d'avenir. Intégration scolaire et éducation interculturelle [A school for the future: Policy statement on educational integration and intercultural education]. Montreal, Quebec: Author.

Ministère de l'Éducation du Québec. (2003). Écoles en action. Intégration, scolarisation et valorisation du français [Schools in action: Integration, schooling and the promotion of the French language; Videocassette]. Direction des services aux communautés culturelles. Montreal, Quebec: Author. 
National Foundation for Educational Research. (2005, April). Raising the achievement of bilingual learners in primary schools (Interim Report). Slough, England: Author.

National Research Council. (1997). Improving schooling for language minority children: A research agenda. Washington, DC: Commission on Behavioral and Social Sciences and Education, Committee on Developing a Research Agenda on the Education of Limited English Proficient and Bilingual Students.

North York Board of Education. (1995). Language for learning: Policy in North York Schools. North York, Ontario: Author.

North York Board of Education (1996). ESL/ESD, reception, orientation, program delivery, monitoring. Document de travail pour les écoles. North York, Ontario: Development Committee.

Office for Standards in Education. (1999). Raising the attainment of minority ethnic pupils, schools and LIA responses. London: HMSO.

Office for Standards in Education. (2003, March). More advanced learners of English as an additional language in secondary schools and colleges. London: HMSO.

Office for Standards in Education. (2005). Could they do even better? The writing of advanced bilingual learners of English at Key Stage 2: HMI survey of good practice. London: HMSO.

Ontario Ministry of Education and Training. (1996, September). Board report. Toronto, Ontario: Author.

Ovando, C., \& Collier, V. P. (1998). Bilingual and ESL classrooms: Teaching in multicultural contexts. Boston: McGraw-Hill.

Passell, J. S. (1998, June). Undocumented immigration to the United States: Numbers, trends and characteristics. Paper presented at the conference, Managing Migration in the 21st Century: On the Politics and Economic of Illegal Immigration, Hamburg, Germany.

Roosens, E. (2007). First language and culture learning in light of globalization: The case of Muslims in Flanders and in the Brussels area. In M. Suarez-Orozco (Ed.), Global understandings: Learning and education in troubled times (pp. 256-271). Berkeley: University of California Press.

Sammons, P., Hillman, J. \& Mortimore, P. (1995). Key characteristics of effective schools: A review of school effectiveness research. London: University of London Institute of Education.

Sensi, D. (1995). Enquête sur les pratiques de partenariat avec les enseignants de langue et de culture d'origine [A study of partnership practices with the teachers of the heritage language and culture: An evaluation of the program]. Audit sur le programme. Liège, Belgium: Université de Liège, Faculté de psychologie et des sciences de l'éducation.

Smeekens, L. (1990). Structural change: From monocultural to bicultural schools. In M. Byram \& J. Leman (Eds.), Bicultural and trilingual education: The Foyer model in Brussels (pp. 136-146). Clevedon, England: Multilingual Matters.

The Stanford Working Group. (1995). Federal education program for limited English proficient students: A blue-print for the second generation. Stanford, CA: Stanford University School of Education.

Swann, L. (1985). Education for All (Final report of the Committee of Inquiry into the education of children from ethnic minorities). London: HMSO. (CMND 9453)

Thomas, W., \& Collier, V. (2002). National Study of School Effectiveness for Language Minority Students Long-Term Academic Achievement. Santa Cruz, CA/Washington, DC: Center for Research on Education Diversity and Excellence.

Top, L., \& de Smedt, H. (2005). Zin voor Talen: taalsensibilisering en de taalportfolio in een meer talig onderwijs [Promoting languages: Language awareness and language portfolio in multilingual education]. Antwerp, Belgium: Garant.

Toronto Board of Education. (1982, March). Towards a comprehensive language policy: Final report of the Work Group on Third Language Instruction. Toronto, Ontario: Author. 
Toronto Board of Education. (1990). ESL/ESD, Handbook of procedures for school and reception welcoming centre staff. Toronto, Ontario, Canada: Author.

Toronto Board of Education. (1994). Supporting language learners in the mainstream classroom. Toronto, Ontario: ESL/ESD Department.

Troyna, D., \& Siraj-Blatchford, I. (1993). Providing support or denying access? The experiences of students designated as ESL and "SN" in a multiethnic secondary school. Education Review, 45, 3-11.

U.S. Department of Education. (1995). Model strategies in bilingual education: Professional development. Washington, DC: Author.

U.S. Department of Education. (2002). Survey of the states' limited English proficiency students and available educational programs and services (2000-2001 summary report). Washington, DC: Author

Waldinger, C. (1997). Which way LA? Immigration and ethnic changes in Southern California. California Policy Seminar Immigration Panel. Retrieved July 8, 2008, from http://migration.ucdavis.edu/rs/more.php?id=108_0_3_0

Zehler, A. M., Fleischman, H. L., Hopstock, P. J., Stephenson, T. G., Pendzick, M., \& Sapru, S . (2003). Descriptive study of Services to LEP students and LEP students with disability (Policy Report: Summary of Findings). Report submitted to the U.S. Department of Education, Office of English Language Acquisition. Washington, DC: The George Washington University, Center for Equity and Excellence in Education.

MARIE MC ANDREW is a full professor in the Department of Educational Administration and Foundations at the University of Montreal, specializing in the education of minorities and intercultural education in a comparative perspective. She holds a Canada Research Chair on Education and Ethnic Relations and has written many articles and books, including Immigration et diversité à l'école : le cas québécois dans une perspective comparative (Immigration and Diversity in Schools: The Quebec Case in a Comparative Perspective) which won the Donner Price in 2001 attributed to the best book on Canadian Public Policy. 